\title{
The Need for Actions Against Polypharmacy in Older People With Frailty
}

\author{
Taro Kojima \\ Department of Geriatric Medicine, Graduate School of Medicine, The University of Tokyo, Tokyo, Japan
}

Corresponding Author:

Taro Kojima, MD, $\mathrm{PhD}$

https://orcid.org/0000-0003-3857-5267

Department of Geriatric Medicine, Graduate School of Medicine, The

University of Tokyo, 7-3-1, Hongo,

Bunkyo-Ku, Tokyo 113-8655, Japan

Tel: +81-3-5800-8652

Fax: +81-3-5800-6530

E-mail: tkojima-tky@umin.ac.jp

Received: June 3, 2018

Revised: June 24, 2018

Accepted: June 29, 2018

\begin{abstract}
Providing safe and effective drug therapy to older patients is challenging for physicians since there is not sufficient evidence to support the efficacy of these drugs and this population is susceptible to adverse drug reactions. Special consideration is needed when treating patients who require nursing care or who are at a stage prior to disability (i.e., frailty) because they may have limited life expectancies, complications, or organ dysfunction. Polypharmacy refers to the condition in which a patient is taking many drugs and, thus, is at an increased risk of adverse events. Although it is difficult to avoid polypharmacy in older people with frailty, the periodic review of drugs and reduction of dose or discontinuation of potentially inappropriate medications are needed to address this problem. This article reviews the association between frailty and polypharmacy and counteractions against polypharmacy in patients with frailty. (Ann Geriatr Med Res 2018;22:111-116)
\end{abstract}

Key Words: Polypharmacy, Drug therapy, Frailty, Potentially inappropriate medications

\section{INTRODUCTION}

Age-related medication changes vary in individuals, but the typical pattern can be described as follows: first, chronic diseases such as hypertension and diabetes are most commonly found in people in their 40s or 50s; then, various diseases such as heart disease, stroke, and cancer have an increased occurrence with age. Since chronic diseases accumulate with age, it is natural that the number of prescription drugs also increases accordingly. During the young and middle-aged period, the use of drugs such as antihypertensive, antihyperlipidemic, and angina treatment drugs may increase but are rarely discontinued unless the disease is cured. Most recently published guidelines do not specifically address the discontinuation of drugs; however, they describe the need to increase drugs when the condition becomes severe. ${ }^{1-4)}$ Furthermore, more drugs are needed when patients have severe complications, such as angina.

Diseases alone do not increase the number of prescription drugs that are needed in old age. Geriatric syndrome is a condition that can cause mixed symptoms related to pathological changes and aging processes, for which drug therapy management is needed because it can affect prognoses. ${ }^{5,6)}$ In addition, conditions such as dysphagia, delirium, depression, and pressure ulcer are increasingly observed in older people aged 75 years or over or in those requiring nursing care and these symptoms are frequently observed in patients with frailty. It is, therefore, understandable that patients with frailty are often exposed to polypharmacy, including analgesics, antipsychotics, antidepressants, hypnotics, and laxatives.

\section{ASSOCIATION BETWEEN FRAILTY AND POLYPHARMACY}

Polypharmacy is generally defined as the concurrent use of a number of drugs. Although there is no strict definition of polypharmacy regarding the number of drugs, studies have defined polypharmacy and hyperpolypharmacy as the use of at least 5 and 10 drugs, respectively.-10)

Frailty refers to a condition prior to disability that requires nursing care. In general, frailty and prefrailty are diagnosed with validated tools such as the Fried criteria; $;{ }^{11)}$ Frailty Index; ${ }^{12)}$ and Fatigue, Resistance, Ambulation, Illness, and Loss of weight (FRAIL) score. ${ }^{13)}$ One outstanding question is if patients with frailty take many prescription drugs. Three cross-sectional studies of relatively healthy cohorts, such as community residents, found that the number of drugs was significantly higher in older people with frailty. ${ }^{14-16)}$ Similarly, cross-sectional studies of older people with frailty reported that frailty was associated with a higher prevalence of polypharmacy ( 5 drugs or more ${ }^{17,18)}$ and hyperpolypharmacy (10 drugs or more). ${ }^{18)} \mathrm{A}$ longitudinal observational study showed that frailty was more frequently observed in patients taking 7 drugs or more (the cutoff point was 6.5). ${ }^{19)}$

Conversely, do polypharmacy patients have an increased prevalence of frailty? Three cross-sectional studies that examined the prevalence of frailty in polypharmacy patients (taking 5 drugs or more) showed that frailty was 
statistically more prevalent among polypharmacy patients, with odds ratios of 1.17 to $1.85^{20-22)}$

Longitudinal studies yielded similar results. A longitudinal study of community residents reported that the frequency of polypharmacy was relatively higher in older people with frailty. ${ }^{23)}$ In contrast, multiple longitudinal studies that examined the prevalence of frailty in polypharmacy patients showed that polypharmacy was significantly associated with frailty, independent of comorbidities, ${ }^{8,10,24-27)}$ which demonstrates that polypharmacy is also a risk factor for diseases and frailty. However, the risk of mortality and the incidence of disabilities were higher in frail patients with polypharmacy than those in nonfrail patients with polypharmacy, with an adjusted odds ratio of 5.3. ${ }^{28)}$ This finding suggests that the concurrence of these 2 conditions is associated with serious problems.

Polypharmacy can be a risk factor for frailty and prefrailty. A previous analysis of community residents 70 years of age or older (mean age, 76.9 \pm 5.5 years, all men) found that healthy people had an odds ratio of 1.73 (95\% confidence interval [CI], 1.30-2.31) for prefrailty per 1 point of drug burden index during a 2-year observation period. ${ }^{8)}$ Given that the drug burden index is defined as the sum of the burdens of anticholinergic and sedative drugs such as hypnotics, increased prescriptions for these drugs may affect the development of prefrailty and accelerate frailty development.

Studies examining the relationship between the number of drugs and frailty development have reported optimal cutoff points to detect frailty of $6^{29)}$ or $6.5,{ }^{19)}$ indicating that patients without frailty who take at least 6 or 7 drugs are at a higher risk of developing frailty.

These findings show that polypharmacy is clearly associated with frailty. Although few studies have examined the association between polypharmacy and sarcopenia, which is closely associated with frailty, one study reported that polypharmacy is associated with sarcopenia independent of comorbidities. ${ }^{30)}$ Therefore, further longitudinal epidemiological studies are needed.

\section{POLYPHARMACY AND FALLS}

Frailty is a risk factor for falls. ${ }^{311}$ Numerous studies have reported polypharmacy to be associated with an increased risk of falls. A cohort study of community residents aged 50 years or over showed that patients taking at least 5 drugs, including antidepressants or benzodiazepines, had a significantly increased risk of falls. ${ }^{32)}$ A longitudinal observational study of outpatients aged 65 years or more showed that patients taking at least 5 drugs had a markedly increased risk of falls, with an odds ratio of $4.50{ }^{33)}$ Although the association between polypharmacy and a tendency to fall cannot be explained by the unitary theory, it may be attributed to the fact that polypharmacy patients often take drugs that inhibit brain activity, such as sedative, antihypertensive, and anticholinergic drugs. It is especially difficult to assess whether drugs actually induce falls. A meta-analysis of the association between drugs and risk of falls in people aged 60 years or more showed that psychotropic and non-steroidal anti-inflammatory and antihypertensive drugs significantly increased the risk of falls. ${ }^{34)}$ The association between antihypertensive drugs and risk of falls remains controversial. An observational study of community residents aged 70 years or more reported that the degree of blood pressure lowering was a significant risk factor for falls and that the risk was not associated with particular antihypertensive drugs. ${ }^{35)}$

At any rate, polypharmacy patients are at a risk of falls because they have many diseases or severe diseases. In addition, since particular drugs that may cause falls may be frequently prescribed in these patients, reviews of drugs are needed to effectively address polypharmacy in older patients with a history of falls or who are at a risk of falls.

\section{DRUG TREATMENT STRATEGY FOR PATIENTS WITH FRAILTY}

Frailty is a stage prior to disability that requires nursing care and can be prevented or reversed to independent functioning through appropriate medical and nursing intervention. For patients with frailty, careful consideration is needed to determine the treatment strategy; according to disease status, the treatment can be curative or supportive. Curative treatments should be preferentially considered when a complete cure is possible, as in the case of surgical treatment for cancer. On the other hand, the supportive treatment of symptoms in accordance with disease progression is the best way to treat patients who are at a risk of adverse events, such as those with poor surgical prognoses, who are at a higher risk in the perioperative period due to organ diseases, and who have refractory postoperative complications.

There are various discussions about treatment objectives for older people with hypertension or diabetes. Recently, treatment guidelines have described special considerations for patients with frailty and older patients with disability. For example, the Japanese Society of Hypertension Guidelines for the Management of Hypertension ${ }^{36)}$ include recommendations for the treatment of older people, patients with dementia, patients with frailty, and older patients with disability. Based on an observational study that reported similar prognoses between patients with and without hypertension among those with slow gait speed or those unable to walk, ${ }^{37)}$ the guidelines stipulate that the treatment of hypertension in patients with slow gait speed should be performed case by case; thus, there is no merit in reducing blood pressure to the normal range for young people. A similar recommendation is made for patients with diabetes. Based on studies that have reported that the development of hypoglycemia due to strict glycemic control may lead to cognitive dysfunction and increased mortality, ${ }^{38-40)}$ the joint committee of the Japan Diabetes 
Society and the Japan Geriatric Society recommends that glycated hemoglobin should not be lowered to below 7.5 in people with frailty or older people with disability, in considerations of cognitive status, activities of daily living, and drug selection. ${ }^{41)}$

For patients with limited life expectancies such as older people with disability and patients with dementia, complete cure is not expected; thus, the treatment objective is to maintain or improve the activities of daily living and quality of life rather than to prolong the prognosis. Therefore, when choosing the best treatment strategy for patients with chronic diseases, clinicians should consider the individualized selection of drugs and treatment objectives for each patient.

\section{FRAILTY AND ADVERSE DRUG REACTIONS}

Polypharmacy can be a risk factor for frailty. In particular, polypharmacy can worsen frailty by causing adverse drug reactions (ADRs). The incidence of ADRs in older people is approximately twice than that in younger people and the frequency of emergency hospitalization due to ADRs in older people is approximately 7 times that in younger people. In addition, patients with small statures and renal dysfunction have a higher prevalence of frailty ${ }^{42,43)}$ and tend to be susceptible to the action of drugs in terms of drug distribution, metabolism, and excretion. In addition, patients who see multiple physicians are likely to be prescribed a greater number of drugs. ${ }^{44)}$ Furthermore, frail patients with depression or dementia may have decreased adherence to prescribed medications and develop adverse events due to the cessation of drugs. ${ }^{45,46)}$

Using fewer drugs is always better for ADR prevention. However, older people are likely to have multiple diseases and require many drugs. In order to address polypharmacy, a careful review of prescription drugs is needed for each patient. In particular, it is important to discontinue or switch high-risk drugs that are likely to cause ADRs or may cause severe ADRs. For example, benzodiazepines have been widely used as hypnotics and are known to induce falls and fractures. The long-term use of benzodiazepines is associated with an increased risk of dementia. ${ }^{47)}$ In addition, anticholinergic drugs dose-dependently increase the risk of dementia or Alzheimer's-type dementia, ${ }^{48)}$ which deserves further attention.

\section{POTENTIALLY INAPPROPRIATE MEDICATION AND SAFE DRUG TREATMENT GUIDELINES IN OLDER PEOPLE}

As described above, the effectiveness of some drugs is uncertain for older people with frailty or disability and certain drugs are associated with increased risks of ADRs. It is, therefore, important to reconsider the need for these drugs. The risk of certain drugs outweighing the potential benefits in older patients is referred to as potentially inappropriate medication (PIM). Overseas, Beers et al. ${ }^{49)}$ devel- oped a list of PIMs in 1991 for older residents in nursing facilities in the United States (Beers criteria). ${ }^{49)}$ The criteria were expanded to include all older patients in 1997 and were revised thrice thereafter. The 2015 Beers criteria consist of several PIM lists: PIMs for older people in general, PIMs that should be avoided depending on condition, and PIMs that should be administered carefully depending on the condition.

In Europe, the Screening Tool of Older Person's Prescriptions and Screening Tool to Alert doctors to Right Treatment (STOPP/START) criteria were published in 2008. After a partial update, the second version of these criteria was published in 2015. ${ }^{50)}$ The Beers and STOPP/START criteria are currently widely used in geriatrics and the field of pharmacy research and clinical practice. Because these overseas criteria are sometimes a poor fit for the therapeutic methods inside the country, the "guidelines for medical treatment and its safety in the elderly," and its PIM list, the screening tool for older person's appropriate prescriptions for Japanese (STOPP-J), were developed. ${ }^{51)}$ These guidelines include flowcharts for physicians considering stopping or decreasing the dose of PIMs or who must prescribe PIMs for older patients. When discontinuing a drug, sudden stoppage might precipitate a sudden exacerbation of the patient's condition; in addition, physicians should consider whether there are better alternatives when starting a new drug prescription. Both tools were developed based on systematic review and discussion by specialists. When there was insufficient evidence, comments from experts in related fields or specialists were incorporated. New drugs were excluded from the guidelines due to insufficient literature. Since safety has not been sufficiently demonstrated for the new drugs, future guidelines should also include safety evaluation.

The reduction of PIMs is important because the use of PIMs increases the mortality rate by 1.6 fold. ${ }^{52)}$ However, a survey of drugs that can cause ADRs showed that ADRs did not always coincide with the upper ranks on the PIM list and that drugs such as oral diabetes and anticoagulant drugs often cause ADRs. ${ }^{53,54)}$ Thus, clinicians should be careful not only for PIMs but also for drugs that are frequently used and tend to cause ADRs. In addition, decreased medication adherence and complex regimens may affect the occurrence of ADRs; therefore, reviews on medications for older patients should be performed in individualized manner.

\section{STRATEGIES TO REDUCE POLYPHARMACY IN JAPAN}

Among clinicians, there has been an increasing concern about polypharmacy in older people. Japan is a super-aged society in which older people account for $26 \%$ or more of the population. ${ }^{55)}$ At least $6,000,000$ people are certified to require nursing care, ${ }^{56)}$ accounting for approximately $20 \%$ of the older population in Japan. A substantial number of patients are frail or with disability, and many of these 
population are thought to have polypharmacy. In Japan, a new rule was introduced under the medical fee revision in 2016 in which 2,500 yen is paid when two or more drugs are discontinued in a patient who had been taking at least 6 drugs. ${ }^{57)}$ This is one of the national strategies intended to address polypharmacy. There has been an increasing use of the guidelines published in 2015 because they were published as a Japanese-language book sold at a reasonable price in medical bookstores or in online shops. Domestic physicians and pharmacists found this format easier to read and use in their clinical practice compared to guidelines written in English. This year, the Ministry of Health, Labour and Welfare issued another guideline on the proper use of drugs in older people, which is expected to promote a review of drugs in older patients across all types of medical institutions in Japan.

Pharmacists will play an important role in reducing polypharmacy in the future. The Japanese Society of Geriatric Pharmacy was established in 2016 by professionals involved in geriatric care (mainly physicians and pharmacists) to promote the research and clinical practice of pharmacists providing geriatric care, including pharmacies, hospitals, and nursing facilities. In addition, the Ministry of Health, Labour and Welfare has been promoting the management of polypharmacy by physicians and pharmacists through the recent revision of the medical fee system in 2016, in which receiving care by "primary care pharmacists" in the pharmacy and the reduction of at least 2 drugs through coordination with medical institutions are evaluated for reimbursement. Governmental support is essential to improve the domestic situation. International coordination is also important to address this issue, especially in East Asian countries where population aging is occurring more rapidly than in other regions.

\section{CONCLUSION}

This study addressed the issue of polypharmacy in older people with frailty or disability who require nursing care. Young and middle-aged patients can be effectively treated with curative drug therapy according to the guidelines; however, we should be aware that such treatment can be harmful to older people with frailty or disability. It is, therefore, important to determine the best strategy based on the condition of each patient. Given the increasing aging population, polypharmacy and frailty will have a greater significance in the future.

\section{CONFLICTS OF INTEREST DISCLOSURES}

The researchers claim no conflicts of interest.

\section{REFERENCES}

1. James PA, Oparil S, Carter BL, Cushman WC, Dennison-Himmelfarb C, Handler J, et al. 2014 evidence-based guideline for the management of high blood pressure in adults: report from the panel members appointed to the Eighth Joint National Committee (JNC 8). JAMA 2014;311:507-20.

2. Mancia G, Fagard R, Narkiewicz K, Redón J, Zanchetti A, Böhm M, et al. 2013 ESH/ESC Guidelines for the management of arterial hypertension: the Task Force for the management of arterial hypertension of the European Society of Hypertension (ESH) and of the European Society of Cardiology (ESC). J Hypertens 2013;31:1281357.

3. Stone NJ, Robinson JG, Lichtenstein AH, Bairey Merz CN, Blum CB, Eckel RH, et al. 2013 ACC/AHA guideline on the treatment of blood cholesterol to reduce atherosclerotic cardiovascular risk in adults: a report of the American College of Cardiology/American Heart Association Task Force on Practice Guidelines. J Am Coll Cardiol 2014 Jul 1;63(25 Pt B):2889-934.

4. Piepoli MF, Hoes AW, Agewall S, Albus C, Brotons C, Catapano AL, et al. 2016 European Guidelines on cardiovascular disease prevention in clinical practice: The Sixth Joint Task Force of the European Society of Cardiology and Other Societies on Cardiovascular Disease Prevention in Clinical Practice (constituted by representatives of 10 societies and by invited experts) Developed with the special contribution of the European Association for Cardiovascular Prevention \& Rehabilitation (EACPR). Eur Heart J 2016;37:2315-81.

5. Lu FP, Chang WC, Wu SC. Geriatric conditions, rather than multimorbidity, as predictors of disability and mortality among octogenarians: a population-based cohort study. Geriatr Gerontol Int 2016;16:345-51.

6. Kane RL, Shamliyan T, Talley K, Pacala J. The association between geriatric syndromes and survival. J Am Geriatr Soc 2012;60:896904.

7. Nishtala PS, Salahudeen MS. Temporal trends in polypharmacy and hyperpolypharmacy in older New Zealanders over a 9-year period: 2005-2013. Gerontology 2015;61:195-202.

8. Gnjidic D, Hilmer SN, Blyth FM, Naganathan V, Cumming RG, Handelsman DJ, et al. High-risk prescribing and incidence of frailty among older community-dwelling men. Clin Pharmacol Ther 2012;91:521-8.

9. Poudel A, Peel NM, Nissen LM, Mitchell CA, Gray LC, Hubbard RE. Adverse outcomes in relation to polypharmacy in robust and frail older hospital patients. J Am Med Dir Assoc 2016;17:767.e9767.e13.

10. Saum KU, Schöttker B, Meid AD, Holleczek B, Haefeli WE, Hauer K, et al. Is Polypharmacy associated with frailty in older people? Results from the ESTHER cohort study. J Am Geriatr Soc 2017;65:e27-32.

11. Fried LP, Tangen CM, Walston J, Newman AB, Hirsch C, Gottdiener J, et al. Frailty in older adults: evidence for a phenotype. J Gerontol A Biol Sci Med Sci 2001;56:M146-56.

12. Rockwood K, Mitnitski A. Frailty in relation to the accumulation of deficits. J Gerontol A Biol Sci Med Sci 2007;62:722-7.

13. Abellan van Kan G, Rolland Y, Bergman H, Morley JE, Kritchevsky SB, Vellas B. The I.A.N.A Task Force on frailty assessment of older people in clinical practice. J Nutr Health Aging 2008;12:29-37.

14. Ballew SH, Chen Y, Daya NR, Godino JG, Windham BG, McAdams-DeMarco M, et al. Frailty, kidney function, and polyphar- 
macy: The Atherosclerosis Risk in Communities (ARIC) Study. Am J Kidney Dis 2017;69:228-36.

15. Jung HW, Yoo HJ, Park SY, Kim SW, Choi JY, Yoon SJ, et al. The Korean version of the FRAIL scale: clinical feasibility and validity of assessing the frailty status of Korean elderly. Korean J Intern Med 2016;31:594-600.

16. Woo J, Leung J. Multi-morbidity, dependency, and frailty singly or in combination have different impact on health outcomes. Age (Dordr) 2014;36:923-31.

17. Merchant RA, Chen MZ, Tan LWL, Lim MY, Ho HK, van Dam RM. Singapore Healthy Older People Everyday (HOPE) Study: prevalence of frailty and associated factors in older adults. J Am Med Dir Assoc 2017;18:734.e9-734.e14.

18. Herr M, Robine JM, Pinot J, Arvieu JJ, Ankri J. Polypharmacy and frailty: prevalence, relationship, and impact on mortality in a French sample of 2350 old people. Pharmacoepidemiol Drug Saf 2015;24:637-46.

19. Gnjidic D, Hilmer SN, Blyth FM, Naganathan V, Waite L, Seibel MJ, et al. Polypharmacy cutoff and outcomes: five or more medicines were used to identify community-dwelling older men at risk of different adverse outcomes. J Clin Epidemiol 2012;65:989-95.

20. Castell MV, Sánchez M, Julián R, Queipo R, Martín S, Otero Á. Frailty prevalence and slow walking speed in persons age 65 and older: implications for primary care. BMC Fam Pract 2013;14:86.

21. Herr M, Sirven N, Grondin H, Pichetti S, Sermet C. Frailty, polypharmacy, and potentially inappropriate medications in old people: findings in a representative sample of the French population. Eur J Clin Pharmacol 2017;73:1165-72.

22. Moulis F, Moulis G, Balardy L, Gérard S, Montastruc F, Sourdet S, et al. Exposure to atropinic drugs and frailty status. J Am Med Dir Assoc 2015;16:253-7.

23. Woo J, Yu R, Wong M, Yeung F, Wong M, Lum C. screening in the community using the FRAIL scale. J Am Med Dir Assoc 2015;16:412-9.

24. Jamsen KM, Bell JS, Hilmer SN, Kirkpatrick CM, Ilomäki J, Le Couteur D, et al. Effects of changes in number of medications and drug burden index exposure on transitions between frailty states and death: the concord health and ageing in men project cohort study. J Am Geriatr Soc 2016;64:89-95.

25. Trevisan C, Veronese N, Maggi S, Baggio G, Toffanello ED, Zambon $\mathrm{S}$, et al. Factors influencing transitions between frailty states in elderly adults: The Progetto Veneto Anziani Longitudinal Study. J Am Geriatr Soc 2017;65:179-84.

26. Wang R, Chen L, Fan L, Gao D, Liang Z, He J, et al. Incidence and effects of polypharmacy on clinical outcome among patients aged 80+: a five-year follow-up study. PLoS One 2015;10:e0142123.

27. Zheng Z, Guan S, Ding H, Wang Z, Zhang J, Zhao J, et al. Prevalence and incidence of frailty in community-dwelling older people: beijing longitudinal study of aging II. J Am Geriatr Soc 2016;64:1281-6.

28. Bonaga B, Sánchez-Jurado PM, Martínez-Reig M, Ariza G, Rodríguez-Mañas L, Gnjidic D, et al. Frailty,polypharmacy, and health outcomes in older adults: the frailty and dependence in albacete study. J Am Med Dir Assoc 2018;19:46-52.

29. Moulis F, Moulis G, Balardy L, Gérard S, Sourdet S, Rougé-Bugat ME, et al. Searching for a polypharmacy threshold associated with frailty. J Am Med Dir Assoc 2015;16:259-61.

30. König M, Spira D, Demuth I, Steinhagen-Thiessen E, Norman K. Polypharmacy as a risk factor for clinically relevant sarcopenia: results from the Berlin Aging Study II. J Gerontol A Biol Sci Med Sci 2017;73:117-22.

31. Kojima G. Frailty as a Predictor of future falls among communitydwelling older people: a systematic review and meta-analysis. J Am Med Dir Assoc 2015;16:1027-33.

32. Richardson K, Bennett K, Kenny RA. Polypharmacy including falls risk-increasing medications and subsequent falls in communitydwelling middle-aged and older adults. Age Ageing 2015;44:90-6.

33. Kojima T, Akishita M, Nakamura T, Nomura K, Ogawa S, Iijima K, et al. Polypharmacy as a risk for fall occurrence in geriatric outpatients. Geriatr Gerontol Int 2012;12:425-30.

34. Woolcott JC, Richardson KJ, Wiens MO, Patel B, Marin J, Khan $\mathrm{KM}$, et al. Meta-analysis of the impact of 9 medication classes on falls in elderly persons. Arch Intern Med 2009;169:1952-60.

35. Tinetti ME, Han L, Lee DS, McAvay GJ, Peduzzi P, Gross CP, et al. Antihypertensive medications and serious fall injuries in a nationally representative sample of older adults. JAMA Intern Med 2014;174:588-95.

36. Shimamoto K, Ando K, Fujita T, Hasebe N, Higaki J, Horiuchi M, et al. The Japanese Society of Hypertension Guidelines for the Management of Hypertension (JSH 2014). Hypertens Res 2014;37: 253-390.

37. Odden MC, Peralta CA, Haan MN, Covinsky KE. Rethinking the association of high blood pressure with mortality in elderly adults: the impact of frailty. Arch Intern Med 2012;172:1162-8.

38. Bruce DG, Davis WA, Casey GP, Clarnette RM, Brown SG, Jacobs IG, et al. Severe hypoglycaemia and cognitive impairment in older patients with diabetes: the Fremantle Diabetes Study. Diabetologia 2009;52:1808-15.

39. Sako A, Yasunaga H, Matsui H, Fushimi K, Hamasaki H, Katsuyama $\mathrm{H}$, et al. Hospitalization for hypoglycemia in Japanese diabetic patients: a retrospective study using a national inpatient database, 2008-2012. Medicine (Baltimore) 2015;94:e1029.

40. Bonds DE, Miller ME, Bergenstal RM, Buse JB, Byington RP, Cutler JA, et al. The association between symptomatic, severe hypoglycaemia and mortality in type 2 diabetes: retrospective epidemiological analysis of the ACCORD study. BMJ 2010;340:b4909.

41. Japan Diabetes Society (JDS)/Japan Geriatric Society (JGS) Joint Committee on Improving Care for Elderly Patients with Diabetes. Committee report: glycemic targets for elderly patients with diabetes. Geriatr Gerontol Int 2016;16:1243-5.

42. Hubbard RE, Lang IA, Llewellyn DJ, Rockwood K. Frailty, body mass index, and abdominal obesity in older people. J Gerontol A Biol Sci Med Sci 2010;65:377-81.

43. Kojima G. Prevalence of frailty in end-stage renal disease: a systematic review and meta-analysis. Int Urol Nephrol 2017;49:198997.

44. Kojima T, Shimada K, Terada A, Nishizawa K, Matsumoto K, Yoshimatsu Y, et al. Association between polypharmacy and multiple uses of medical facilities in nursing home residents. Geriatr Gerontol Int 2016;16:770-1.

45. Ferguson C, Inglis SC, Newton PJ, Middleton S, Macdonald PS, Davidson PM. Barriers and enablers to adherence to anticoagula- 
tion in heart failure with atrial fibrillation: patient and provider perspectives. J Clin Nurs 2017;26:4325-34.

46. Steinman MA, Hanlon JT, Sloane RJ, Boscardin WJ, Schmader $\mathrm{KE}$. Do geriatric conditions increase risk of adverse drug reactions in ambulatory elders? Results from the VA GEM Drug Study. J Gerontol A Biol Sci Med Sci 2011;66:444-51.

47. Billioti de Gage S, Moride Y, Ducruet T, Kurth T, Verdoux H, Tournier M, et al. Benzodiazepine use and risk of Alzheimer's disease: case-control study. BMJ 2014;349:95205.

48. Gray SL, Anderson ML, Dublin S, Hanlon JT, Hubbard R, Walker R, et al. Cumulative use of strong anticholinergics and incident dementia: a prospective cohort study. JAMA Intern Med 2015;175: 401-7.

49. By the American Geriatrics Society 2015 Beers Criteria Update Expert Panel. American Geriatrics Society 2015 Updated Beers Criteria for Potentially Inappropriate Medication Use in Older Adults. J Am Geriatr Soc 2015;63:2227-46.

50. O'Mahony D, O'Sullivan D, Byrne S, O'Connor MN, Ryan C, Gallagher P. STOPP/START criteria for potentially inappropriate prescribing in older people: version 2. Age Ageing $2015 ; 44: 213-8$.

51. Kojima T, Mizukami K, Tomita N, Arai H, Ohrui T, Eto M, et al. Screening Tool for Older Persons' Appropriate Prescriptions for Japanese: Report of the Japan Geriatrics Society Working Group on "Guidelines for medical treatment and its safety in the elderly". Geriatr Gerontol Int 2016;16:983-1001.

52. Muhlack DC, Hoppe LK, Weberpals J, Brenner H, Schöttker B. The association of potentially inappropriate medication at older age with cardiovascular events and overall mortality: a systematic review and meta-analysis of cohort studies. J Am Med Dir Assoc 2017;18:211-20.

53. Budnitz DS, Pollock DA, Weidenbach KN, Mendelsohn AB, Schroeder TJ, Annest JL. National surveillance of emergency department visits for outpatient adverse drug events. JAMA 2006;296:185866.

54. Budnitz DS, Lovegrove MC, Shehab N, Richards CL. Emergency hospitalizations for adverse drug events in older Americans. N Engl J Med 2011;365:2002-12.

55. Ministry of Health, Labour, and Welfare. I. Overview of the system and the basic statistics. 01 General Welfare and Labour [Internet]. Tokyo: Ministry of Health, Labour, and Welfare; [cited 2018 May 20]. Available from: http://www.mhlw.go.jp/english/wp/wp-hw11/ dl/01e.pdf.

56. Ministry of Health, Labour, and Welfare. I. Overview of the system and the basic statistics. 10 Health and Welfare Services for the Elderly [Internet]. Tokyo: Ministry of Health, Labour, and Welfare; [cited 2018 May 20]. Available from: http://www.mhlw.go.jp/ english/wp/wp-hw11/dl/10e.pdf.

57. Ministry of Health, Labour, and Welfare. The 2018 revision of medical fee reimbursement [Internet]. Tokyo: Ministry of Health, Labour, and Welfare; [cited 2018 May 20]. Available from: http:// www.mhlw.go.jp/stf/seisakunitsuite/bunya/0000188411.html. 